\title{
Anesthesia with ketamine-propofol versus remifentanil-propofol from the perspective of children, their caregivers, gastroenterologists and recovery room staff
}

\author{
Damps Maria ${ }^{1}$, Stołtny Ludwik ${ }^{1}$, Kucewicz- Czech Ewa ${ }^{2}$ \\ ${ }_{1}^{1}$ Department of anaesthesiology and intensive care, John Paul II Upper Silesian Child Health Centre, Katowice, Poland \\ ${ }^{2}$ Department of anaesthesiology and intensive care with cardiac monitoring, Upper-Silesian Medical Centre, Katowice, Poland
}

\section{BACKGROUND AND GOAL OF STUDY}

Most children require general anesthesia to perform gastroscopy. A better understanding of the opinion on the procedure may help to improve the anesthetic technique. The aim of the study was to compare anesthesia using ketamine-propofol versus remifentanilpropofol in terms of the opinion of patients and their parents, endoscopists and recovery room staff.

\section{MATERIALS AND METHODS}

The prospective, randomized, single blind study included 90 children anesthetized for scheduled gastroscopy. Intravenous anesthesia with maintained spontaneous respiration was used. Group K included children anesthetized with ketamine and propofol, Group R children anesthetized with remifentanil and propofol. In order to obtain the opinion of children and their parents, an anonymous questionnaire was completed in the afternoon, after anesthesia. At the end of the examination, the endoscopist assessed the conditions of endoscopic examination. The recovery room nurses defined time to return of consciousness, the behavior of children after regaining consciousness. Statistical analysis was performed using the STATISTICA 12 software.

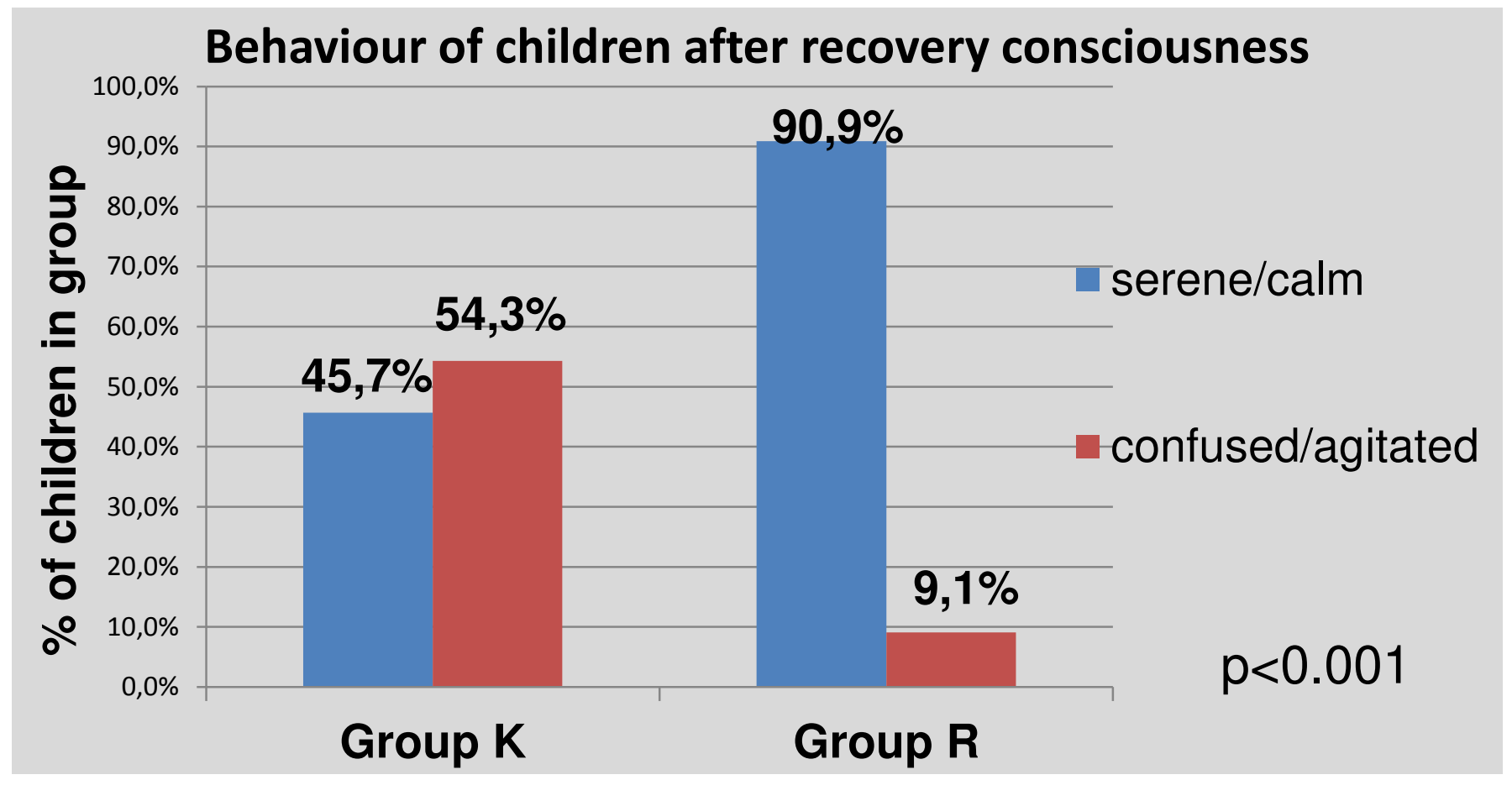

RESULTS
Patients opinion on the most difficult procedure moment, $p=N S$

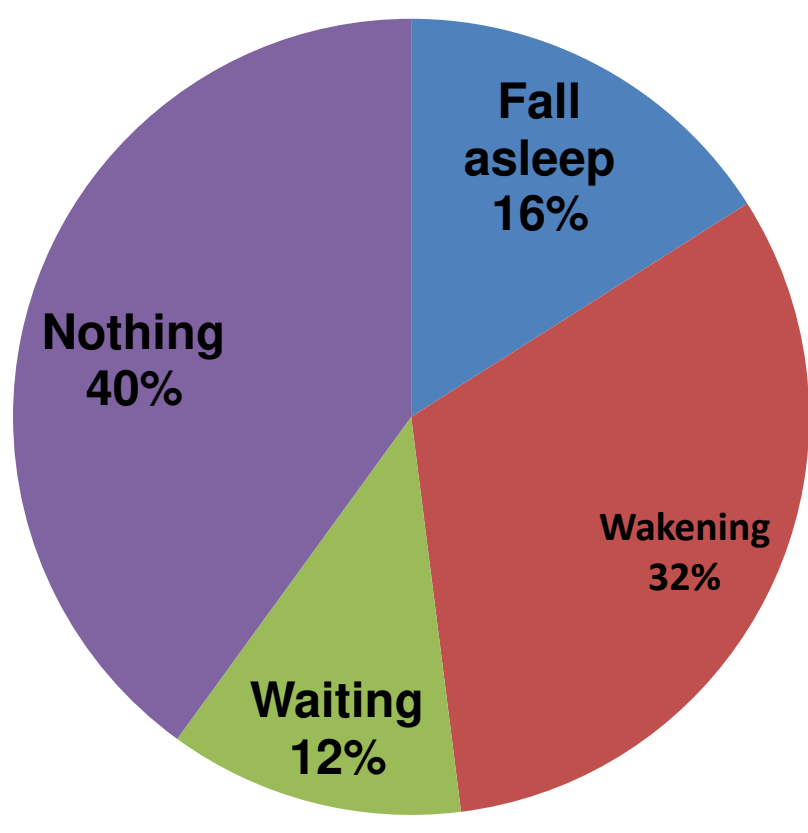

Group K

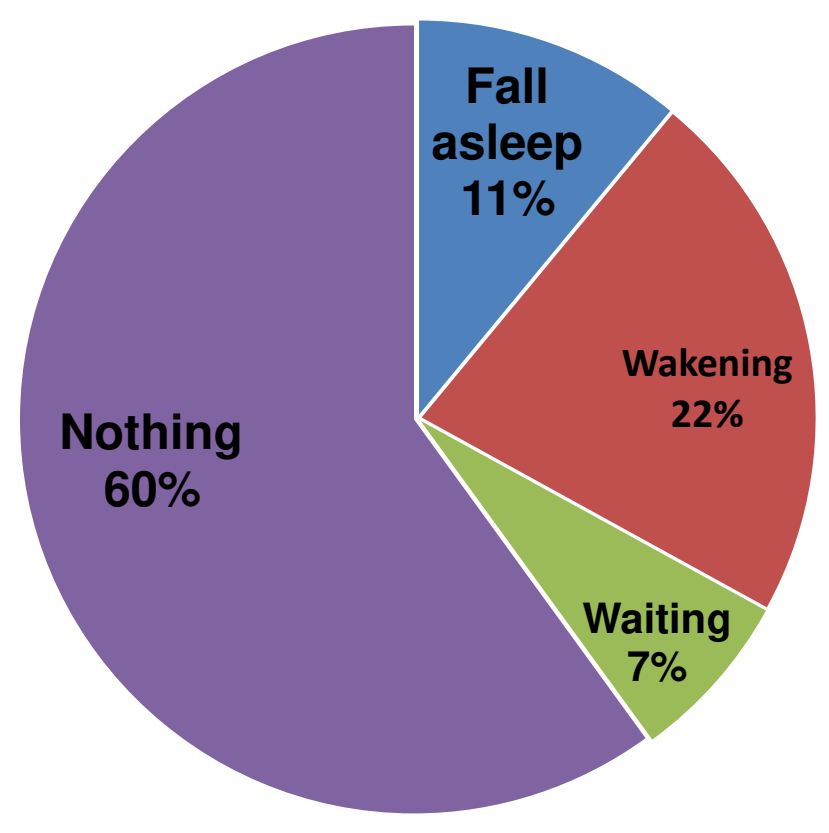

Group R

The children completed 31 questionnaires in Group K and 27 in Group R. All children who completed the questionnaire favorably evaluated the course of anesthesia. There was no significant difference between the groups in the assessment of the worst moment $(p=0.96)$. A statistically significant difference was in remembering the moment of falling asleep in Group $R(p<0.001)$ and dizziness after anesthesia in Group K ( $p<0.05$ ). The parents completed 36 questionnaires in Group R and 39 in Group K. All parents were satisfied with the cooperation with the anesthesiologist and favorably assessed the course of anesthesia. There was no significant difference in the assessment of the child's condition after anesthesia $(p=0.99)$ or the occurrence of disturbing symptoms $(p=0.89)$. There were statistically significant differences in assessing the conditions of examination by the gastroenterologist $(p<0.05)$ in favor of Group K. The time to return of consciousness and the behavior of the child after recovery was significantly different in the groups $(p<0.01 ; p<0.001)$.

Standard pharmacotherapy in both groups,including intervention doses

\begin{tabular}{|l|l|}
\hline \multicolumn{1}{|c|}{ Group K } & \multicolumn{1}{c|}{ Group R } \\
\hline Induction: & Induction: \\
Ketamine i.v., $1.5 \mathrm{mg} / \mathrm{kg} \mathrm{bw}$ & Remifentanil i.v., $0.1 \mu \mathrm{g} / \mathrm{kg} \mathrm{bw} / \mathrm{min}$. \\
Propofol i.v. dose $1.5 \mathrm{mg} / \mathrm{kg} \mathrm{bw}$ & Propofol i.v. $1.5 \mathrm{mg} / \mathrm{kg} \mathrm{bw}$ \\
Maintenance of anaesthesia: & Maintenance of anaesthesia: \\
Propofol infusion $6 \mathrm{mg} / \mathrm{kg} \mathrm{bw} / \mathrm{h}$ & Propofol infusion $6 \mathrm{mg} / \mathrm{kg} \mathrm{bw} / \mathrm{h}+$ \\
& remifentanil infusion $0.1 \mu \mathrm{gg} / \mathrm{kg}$ \\
If necessary, an additional dose of & bw/min. \\
propofol i.v. $0.5 \mathrm{mg} / \mathrm{kg}$ bw & If necessary, an additional dose of \\
\hline
\end{tabular}

\begin{tabular}{ccccc}
\hline & Group K & Group R & p \\
\hline $\begin{array}{c}\text { Time to return of } \\
\text { consciousness } \\
\text { (minutes) }\end{array}$ & Mediana \pm IR & $6 \pm 5$ & $4 \pm 4,5$ & \\
\hline
\end{tabular}

$\square$ The combination of ketamine with propofol provides very good conditions for endoscopic examination, with more frequent confusion after regaining consciousness

पThe combination of propofol and remifentanil provides fast recovery of consciousness and cheerful mood after waking up

- Both anesthesia methods have been favorably assessed by patients and their caregivers

\section{CONCLUSIONS}

